\title{
Causal Factors Implicated in Research Misconduct: Evidence from ORI Case Files
}

\section{Mark S. Davis • Michelle Riske-Morris •}

Sebastian R. Diaz

Published online: 9 May 2008

(C) Springer Science+Business Media B.V. 2008

\section{Erratum to: Sci Eng Ethics \\ DOI 10.1007/s11948-007-9045-2}

Unfortunately an incorrect Fig. 2 was published in the article. Below is the correct Figure.

The online version of the original article can be found under doi:10.1007/s11948-007-9045-2.

M. S. Davis $(\bowtie)$

Criminal Justice Research Center, The Ohio State University, 147 Journalism Building, 242 West 18th Avenue, Columbus, OH 43210, USA

e-mail: davis.198@socioloy.osu.edu

M. Riske-Morris

Justice Research \& Advocacy, Inc., Amherst, OH, USA

S. R. Diaz

College of Human Resources and Education, West Virginia University, Morgantown, WV, USA 
Dendrogram using Average Linkage (Between Groups)

Rescaled Distance Cluster Combine

Label C A S E Num

Pressure to Produce

Pressure on Self/Over-Committed

Supervisor Expectations

Denial of Negative Intent

Cognitive Deficiency

Poor Judgment/Carelessness

Stress/Pressure in General

Overworked/Insufficient Time

Denial of an Injury

Personal Problems

Psychological Problems

Lack of support system

Personal Insecurities

Stressful Job

Desire to Succeed/Please

Insecure Position

Insufficient Supervision/Mentoring Non-collegial Work Environment

Professional Conflicts

Substandard Lab Procedures

Reliance on Others/Permission

Condemnation of the Condemner

Poor Communication/Coordination

Lost/Stolen/Discarded Data

Jumping the Gun

Lie to Preserve the Truth

Lack of Control

Inappropriate Responsibility

Competition for Position

Poor Supervisor (Respondent)

Language Barrier

Character Flaw

Recognition

Laziness

Impatient

Public Good Over Science

Amnesia

Difficult Job/Tasks

Frustrated

Restoring Equity

Slippery Slope

Fear

Avoid Degradation

Apathy/Dislike/Desire to Leave

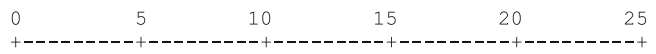

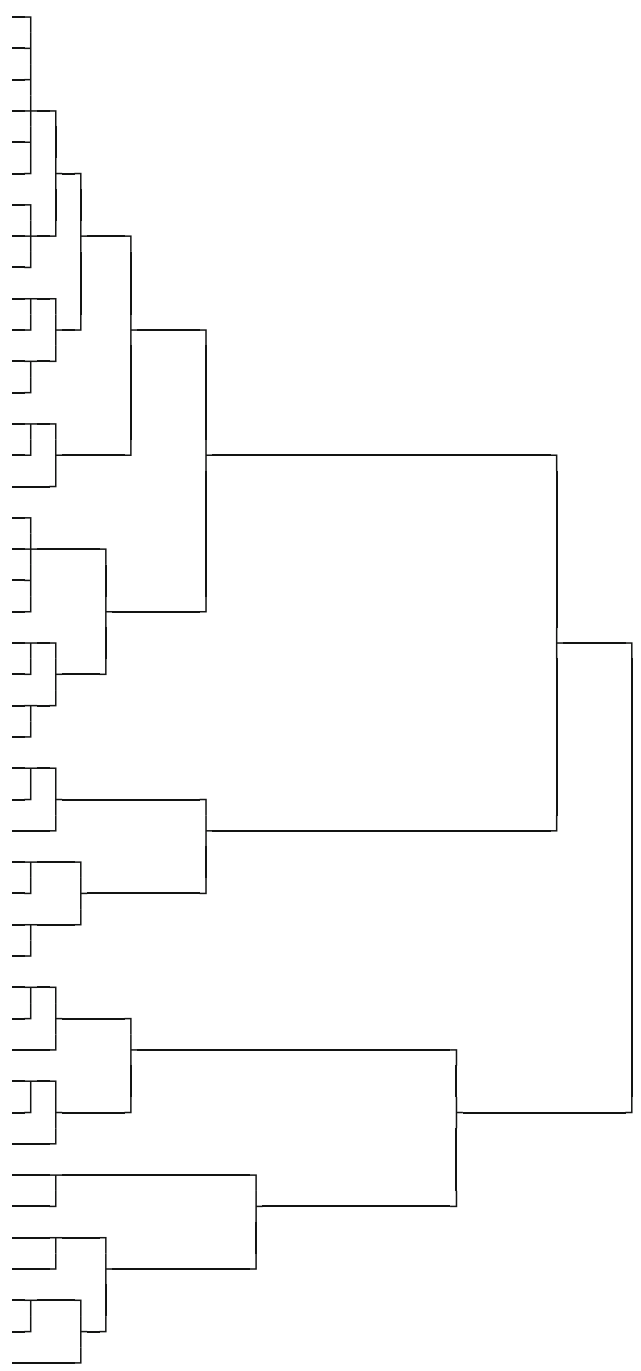

Fig. 2 Dendogram of the 44 concepts 